\title{
The Effects of Some Prebiotic Products (Actigen, Biotronic Top3) on the Production and Consumption Indices in Broiler Chickens
}

\author{
Mihai-Iacob BENȚEA ${ }^{1 *}$, Radu MARȚI ${ }^{2}$, Aurel ŞARA ${ }^{1}$, Ionel TOADER ${ }^{1}$, Erol- Florian GABOR ${ }^{3}$ \\ ${ }^{1}$ University of Agricultural Sciences and Veterinary Medicine Cluj-Napoca, Romania \\ ${ }^{2}$ Biomin, Romania \\ ${ }^{3}$ Momaja Expert SRL \\ * corresponding author: mihai.bentea@usamvcluj.ro
}

Bulletin UASVM Animal Science and Biotechnologies 73(2)/ 2016

Print ISSN 1843-5262; Electronic ISSN 1843-536X

DOI:10.15835/buasvmcn-asb: 12237

\begin{abstract}
The prebiotics are natural or synthetic organic substances that favour the growth of beneficial microorganisms in the gastro-intestinal tract, thus maintaining the animals healthy and productive and subsequently increasing the production performances. The aim of this study was to evaluate the effects of prebiotic products (Actigen and Biotronic Top3) on the main production and consumption indices of broilers. The study was conducted on a 75 broiler chicken Ross-308 hybrids divided in three groups, over a period of 42 days. Group 1(E) received combined feeds with the Actigen prebiotic for 42 days as follows: $0.08 \%$ in the starter phase (1-14 days), $0.04 \%$ in the grower phase (14-35 days) and $0.02 \%$ in the finishing phase (35-42 days). The broilers in group 2(E) were administered feeds containing prebiotic Biotronic Top3 (0.1\%) for the whole duration of the study. The broilers in the control group were fed with the base feed only. The broilers from all groups were weighed at the beginning and every following week; their average body weight, daily weight gain, feed consumption and feed conversion ratio (FCR) were determined. The use of the Actigen in experimental group 1(E) led to a body mass increase of $11.26 \%$, to an $11.54 \%$ higher daily weight gain and to the reduction of the FCR by $2.31 \%$ compared to the control group. In Group 2(E) receiving Biotronic Top3, an increase was recorded for the body mass $(9.25 \%)$ and daily weight gain $(9.49 \%)$, the FCR being the same as the one recorded in the control group. These results confirm the favourable influence of prebiotics on the production performances of broiler chickens.
\end{abstract}

Keywords: Actigen, Biotronic Top3, broiler chicken, production performance

\section{INTRODUCTION}

Prebiotics are substances of organic origin, natural or synthesized, that favour the development of useful microorganisms in the gastro-intestinal tract, thus contributing to a good general health status and to the increase of the productive performances of the animals. An efficacious oligosaccharide-based prebiotic is Actigen, produces by the Kentucky-based Alltech ${ }^{\circledR}$ Company, extracted from the cellular wall of the Saccharomyces cerevisiae yeast, grown on a complex sugar medium.
Actigen (Alltech ${ }^{\circledR} \mathrm{Inc}$ ) is a second-generation prebiotic product, containing mannan-oligosaccharides (MOS), extracted from the cellular wall of the Saccharomyces cerevisiae var. Boulardii (SCvB). This product is considered to be a growth promoter by its roles in enhancing the immune response, the production parameters and the general health status.

In researches carried out worldwide, the use of Actigen determined the improvement of the final body mass of broiler chickens, the improvement of the weight gain, the feed conversion rate (FCR) 
and the reduction of losses caused by mortalities (Hooge, 2013).

Lea et al. (2011) noted that the administration of Actigen in a dose of $200 \mathrm{~g} / \mathrm{t}$ feed, yielded the best results regarding the body mass and the FCR in the experimental group (2.85g and 1.73), compared to the control group (2.52g and 1.74). Similar results regarding the effect of Actigen on the production performances in broiler chicken were reported by Nollet (2010), Peric et al. (2010), Culver et al. (2011), Lausten et al. (2011), Olejniczak et al. (2011) and by Mathis (2012). Actigen improves the overall status of the immune system of the chickens, also reducing the mortality rates recorded during all the growth phases (Gernat et al., 2011).

Biotronic Top3 is prebiotic based on organic acids (formic, acetic, propionic, lactic citric and sorbic acid), their salts and phytochemical products, developed by Biomin Austria. The class of prebiotics that contains Biotronic Top3, controls the multiplication of the gram-negative bacteria (E. coli, Salmonella) (Ferket, 2005), thus ensuring a better feed conversion, enhancing the growth performances and increasing the economic efficiency, when used in fed destined for cattle, swine, poultry and fish (Biomin, 2016).

The aim of this research was to determine the effects of some prebiotic products (Actigen and Biotronic Top3) on the main production and consumption indices in broiler chickens.

\section{MATERIALS AND METHODS}

The research was carried out over a period of 42 days (8 December 2015- 19 January 2016) in a private farm, on a number of 75 Ross-308 hybrid chickens. The chickens were randomly assigned to three groups (25 birds/group), as follows: experimental Group 1, receiving a base diet supplemented with Actigen $0.08 \%$ in the first growing phase (1-14 days), $0.04 \%$ in the second phase (14-35 days) and $0.02 \%$ in the third phase (35-42 days); experimental Group 2 receiving the base diet supplemented with Biotronic Top3 $(0.1 \%)$ throughout the whole growth period; the third group acted as the Control Group and received only the base diet. The birds were maintained in a deep litter system, in similar conditions of microclimate, density, nourishment and feeding regime. The base diet was the same for all three groups and had the same energetic and protein level (Phase I: energy - 3051 kcal $/ \mathrm{kg}$, crude protein - 22.76\%; Phase II: energy - 3134 $\mathrm{kcal} / \mathrm{kg}$, crude protein - 21.31\%; Phase III: energy - $3144.4 \mathrm{kcal} / \mathrm{kg}$, crude protein - 19.94\%).

During the experimental period the following indices were observed and recorded: body mass evolution, weight gain, feed consumption and feed conversion ratio. The chickens were weighted at the beginning of the experiment and every week until the age of 42 days.

The results were statistically analysed by means of the Student test, using the GraphPad InStat software, ver. 3.10.

\section{RESULTS AND DISCUSSION}

The mean values and the variability of body mass recorded in chickens, during the experimental period are presented in Tab. 1 .

At the beginning of the experimental period, the birds in the three groups were uniform with regard to the body mass. After three weeks, the differences recorded between the control group and the experimental groups started to increase,

Tab. 1. Mean values and variability of body mass in broiler chickens (g/bird)

\begin{tabular}{|c|c|c|c|c|c|c|}
\hline \multirow[t]{2}{*}{ Age (weeks) } & \multicolumn{2}{|l|}{$\begin{array}{c}\text { Control } \\
\mathrm{n}=25 \\
\end{array}$} & \multicolumn{2}{|c|}{$\begin{array}{c}\text { Group 1(E) } n=25 \\
\text { ACTIGEN }\end{array}$} & \multicolumn{2}{|c|}{$\begin{array}{c}\text { Group 2(E) n=25 } \\
\text { BIOTRONIC TOP } 3\end{array}$} \\
\hline & $\mathrm{X} \pm \mathrm{SX}$ & $\mathrm{V} \%$ & $\mathrm{X} \pm \mathrm{SX}$ & V \% & $\mathrm{X} \pm \mathrm{SX}$ & $\mathrm{V} \%$ \\
\hline 1 day old & $62.16 \pm 0.25$ & 2.06 & $62.68 \pm 0.20$ & 1.58 & $62.24 \pm 0.22$ & 1.75 \\
\hline 1 & $212.8 \pm 5.67$ & 13.33 & $222.08 \pm 4.26$ & 9.59 & $222.12 \pm 5.42$ & 12.20 \\
\hline 2 & $475.32 \pm 8.98$ & 9.45 & $497.04 \pm 10.41$ & 10.47 & $486.48 \pm 13.19$ & 13.56 \\
\hline 3 & $862.6 \pm 20.19$ & 11.70 & $959.6^{* *} \pm 18.78$ & 9.78 & $934.0^{*} \pm 25.07$ & 13.41 \\
\hline 4 & $1379.6 \pm 31.25$ & 11.33 & $1564.8^{* *} \pm 31.24$ & 9.98 & $1536^{* *} \pm 41.22$ & 13.42 \\
\hline 5 & $1923.4 \pm 45.78$ & 11.90 & $2180.4^{* * *} \pm 39.71$ & 9.11 & $2160.6^{* * *} \pm 50.44$ & 11.67 \\
\hline 6 & $2442.4 \pm 63.45$ & 12.99 & $2717.4^{* *} \pm 53.56$ & 9.86 & $2668.4^{* *} \pm 57.82$ & 10.83 \\
\hline
\end{tabular}


being significant $(934.0 \pm 25.07 \mathrm{~g}$ in group $2 \mathrm{E}$ Biotronic compared to the control group; $\mathrm{p}<0.05$ ) or very significant $(959.6 \pm 18.78 \mathrm{~g}$ in group $1 \mathrm{E}$ Actigen compared to the control group; $\mathrm{p}<0.01$ ). At the end of the fifth week (the second growth phase), the highest body weight was recorded in group $1 \mathrm{E}$ receiving Actigen $(2180.4 \pm 39.71 \mathrm{~g})$ followed by group 2E receiving Biotronic (2160.6 $\pm 50.44 \mathrm{~g}$ ); the control group had the lowest body mass value (1923.4 $\pm 45.78 \mathrm{~g})$. By the end of the sixth week (finishing phase) the differences were very significant, being $275 \mathrm{~g}$ higher in Group 1E and 226 g higher in Group 2E compared to the control group, thus indicating a good influence of the to prebiotics on the chicken's body weight. Similar results regarding the effects of prebiotics on body weight were reported by Nollet (2010), Peric et al. (2010), Culver et al. (2011) and by Olejniczak et al. (2011).

The body weight was higher in the experimental groups (Tab. 2, overleaf) throughout the six weeks of growth, being $11.26 \%$ higher in the Actigen group and $9.25 \%$ higher in the Biotronic group, compared to the control.

A higher daily weight gain was recorded in the experimental groups, compared to the control group (Table 3). The recorded values were $5.15 \%$ higher in the Actigen group co pared to the control and $2.68 \%$ higher in the Biotronic fed group, when compared to the control group. In the second growth phase, again, the chicken from the experimental groups showed a higher daily weight gain, with recorded mean values of 80.16 $\mathrm{g} /$ day in the Actigen group and $79.72 \mathrm{~g} /$ day in the Biotronic group, compared to only $68.96 \mathrm{~g} /$ day in the control group. At the end of the experimental period, the daily weight gain was $11.54 \%$ higher in the Actigen group and $9.49 \%$ higher in the Biotronic group compared to the control group; these results are comparable to those reported by Hooge (2013), Peric et al. (2010), Lausten et al. (2011), Mathis (2012).

Regarding the average daily consumption, a gradual increase was recorded with age, the final recorded mean being $98.01 \mathrm{~g} /$ day in the control

Tab. 2. Body mass evolution throughout the experimental period

\begin{tabular}{ccccc}
\hline Issue & U.M. & Control & $\begin{array}{c}\text { Group 1(E) } \\
\text { Actigen }\end{array}$ & $\begin{array}{c}\text { Group 2(E) } \\
\text { Biotronic Top3 }\end{array}$ \\
\hline Initial & $\mathrm{g}$ & 62.16 & 62.68 & 62.24 \\
\hline & $\%$ & 100.00 & 100.84 & 100.13 \\
\hline Phase I (1-14 days) & $\mathrm{g}$ & 475.32 & 497.04 & 486.48 \\
\hline & $\%$ & 100.00 & 104.57 & 102.35 \\
\hline Phase II (15-35 days) & $\mathrm{g}$ & 1923.40 & 2180.40 & 2160.60 \\
\hline Phase III (36-42 days) & $\%$ & 100.00 & 113.36 & 112.33 \\
\hline & $\mathrm{g}$ & 2442.40 & 2717.40 & 109.25 \\
\hline
\end{tabular}

Tab. 3. The daily weight gain evolution in the broiler chicken (g/bird)

\begin{tabular}{ccccc}
\hline Issue & U.M. & Control & $\begin{array}{c}\text { Group 1(E) } \\
\text { ACTIGEN }\end{array}$ & $\begin{array}{c}\text { Group 2(E) } \\
\text { BIOTRONIC TOP 3 }\end{array}$ \\
\hline Phase I (1-14 days) & $\mathrm{g}$ & 29.51 & 31.03 & 30.30 \\
\hline & $\%$ & 100.00 & 105.15 & 102.68 \\
\hline \multirow{2}{*}{ Phase II (15-35 days) } & $\mathrm{g}$ & 68.96 & 80.16 & 79.72 \\
\cline { 2 - 5 } & $\%$ & 100.00 & 116.24 & 115.60 \\
\hline \multirow{2}{*}{ Phase III (36-42 days) } & $\mathrm{g}$ & 74.14 & 76.71 & 72.54 \\
\cline { 2 - 5 } & $\%$ & 100.00 & 103.47 & 97.84 \\
\hline $\begin{array}{c}\text { Mean (for the whole } \\
\text { experimental period) }\end{array}$ & $\mathrm{g}$ & 56.67 & 63.21 & 62.05 \\
\cline { 2 - 5 } & $\%$ & 100.00 & 111.54 & 109.49 \\
\hline
\end{tabular}


group, $106.6 \mathrm{~g} /$ day in the Actigen fed group and $107.3 \mathrm{~g} /$ day in the Biotronic fed group. A higher increase of the daily consumption was recorded in the experimental groups, by $8.76 \%$ (group 1E) and $9.48 \%$ (group 2E), determined by the higher average daily gain recorded in the experimental groups, compared to the control group.

The data in Tab. 5 (overleaf) presents that, with age, the chickens consume more feeds per $\mathrm{kg}$ bodyweight. The chickens in the Actigen group had the lowest FCR, ranging from $1.21 \mathrm{~kg}$ feed $/ \mathrm{kg}$ weight gain, at the start of the first phase, to 2.52 $\mathrm{kg}$ feed $/ \mathrm{kg}$ weight gain, at the end of the last phase, with a mean value of $1.69 \mathrm{~kg}$ feed/ $\mathrm{kg}$ weight gain, followed by the Biotronic group and the control group, both having the same value $(1.73 \mathrm{~kg}$ feed $/ \mathrm{kg}$ weight gain). Similar result has been reported by Peric et al. (2010), Lea et al. (2011) or Olejniczak et al. (2011).
The mean production and consumption indices recorded throughout the experimental period are presented in Tab. 6 (overleaf).

The best results were recorded for the chicken in the Actigen group, which showed the highest weight gain, the highest daily weight gain $(63.21 \mathrm{~g})$ and the lowest feed conversion ratio $(1.69 \mathrm{~kg}$ feed/kg weight gain, throughout the experimental period, thus confirming the results reported by Nollet et al. (2010), Culver et al. (2011), Gernat (2011), Lausten et al. (2011), Olejniczak et al. (2011).

\section{CONCLUSION}

The use of Actigen and Biotronic Top3 determined a significant improvement of the main production and consumption indices of broiler chicken.

The use of Actigen determined the increase of the body weight by $11.26 \%$, increased the

Tab. 4. Evolution of average daily feed consumption throughout the experimental period

\begin{tabular}{ccccc}
\hline \multirow{2}{*}{ Issue } & & \multicolumn{4}{c}{ Groups } \\
\cline { 2 - 5 } & U.M. & L(M) & $\begin{array}{c}\text { G1(E) } \\
\text { ACTIGEN }\end{array}$ & $\begin{array}{c}\text { G2(E) } \\
\text { BIOTRONIC TOP 3 }\end{array}$ \\
\hline Phase I (1-14 days) & $\mathrm{g}$ & 36.57 & 37.71 & 37.20 \\
\hline \multirow{2}{*}{ Phase II (15-35 days) } & $\%$ & 100.00 & 103.12 & 101.72 \\
\hline \multirow{2}{*}{ Phase III (36-42 days) } & $\mathrm{g}$ & 109.59 & 123.52 & 124.40 \\
\cline { 2 - 5 } & $\%$ & 100.00 & 112.71 & 113.51 \\
\hline $\begin{array}{c}\text { Mean value at the end of the } \\
\text { experimental period }\end{array}$ & $\mathrm{g}$ & 186.14 & 193.63 & 196.23 \\
\cline { 2 - 5 } & $\mathrm{g}$ & 100.00 & 104.02 & 105.42 \\
\hline
\end{tabular}

Tab. 5. Evolution of the feed conversion ratio throughout the experimental period

\begin{tabular}{|c|c|c|c|c|}
\hline \multirow[b]{2}{*}{ Issue } & \multirow[b]{2}{*}{ U.M. } & \multicolumn{3}{|c|}{ Groups } \\
\hline & & $\begin{array}{l}\text { Control } \\
\text { group }\end{array}$ & $\begin{array}{l}\text { Group 1(E) } \\
\text { ACTIGEN }\end{array}$ & $\begin{array}{c}\text { Group 2(E) } \\
\text { BIOTRONIC TOP } 3\end{array}$ \\
\hline \multirow{2}{*}{ Phase I (1-14 days) } & $\mathrm{kg} / \mathrm{kg}$ & 1.24 & 1.21 & 1.23 \\
\hline & $\%$ & 100.00 & 97.58 & 99.19 \\
\hline \multirow{2}{*}{ Phase II (15-35 days) } & $\mathrm{kg} / \mathrm{kg}$ & 1.59 & 1.54 & 1.56 \\
\hline & $\%$ & 100.00 & 96.86 & 98.11 \\
\hline \multirow{2}{*}{ Phase III (36-42 days) } & $\mathrm{kg} / \mathrm{kg}$ & 2.51 & 2.52 & 2.70 \\
\hline & $\%$ & 100.00 & 100.40 & 107.57 \\
\hline \multirow{2}{*}{$\begin{array}{l}\text { Mean (for the whole } \\
\text { experimental period) }\end{array}$} & $\mathrm{kg} / \mathrm{kg}$ & 1.73 & 1.69 & 1.73 \\
\hline & $\%$ & 100.00 & 97.69 & 100.00 \\
\hline
\end{tabular}


Tab. 6. Mean production and consumption indices recorded throughout the experimental period

\begin{tabular}{ccccc}
\hline \multirow{2}{*}{ Issue } & U.M. & Control group & $\begin{array}{c}\text { Group 1(E) } \\
\text { ACTIGEN }\end{array}$ & $\begin{array}{c}\text { Group 2(E) } \\
\text { BIOTRONIC TOP 3 }\end{array}$ \\
\hline \multirow{2}{*}{ Body weight } & Initial (g) & 62.16 & 62.68 & 62.24 \\
\cline { 2 - 5 } & Final (g) & 2442.40 & 2717.40 & 2668.40 \\
\cline { 2 - 5 } & Final (\%) & 100.00 & 111.26 & 109.25 \\
\hline \multirow{2}{*}{ Daily weight gain } & $\mathrm{g}$ & 56.67 & 63.21 & 62.05 \\
\cline { 2 - 5 } & $\%$ & 100.00 & 111.54 & 109.49 \\
\hline Daily feed \\
\cline { 2 - 5 } consumption & $\mathrm{g}$ & 98.01 & 106.60 & 109.48 \\
\hline \multirow{2}{*}{ Feed conversion ratio } & $\mathrm{kg} / \mathrm{kg}$ & 100.00 & 108.76 & 1.73 \\
\cline { 2 - 5 } & $\%$ & 100.00 & 1.69 & 100.00 \\
\hline
\end{tabular}

daily weight gain by $11.54 \%$ and also decreased the feed conversion ratio by $2.31 \%$, throughout the whole experimental period, compared to the control group.

Favourable results have also been recorded with the use of Biotronic Top3, which determined an improvement of the final body weight by $9.25 \%$ and the improvement of the daily weight gain by 9.49\% when compared to the control group. The feed conversion index was the same as the one recorded in the control group.

Based on the recorded results, we recommend the use of these two prebiotics (Actigen and Biotronic Top3) in broiler chicken, for improving the gain weight and the feed conversion in this species.

\section{REFERENCES}

1. Culver J and Nollet L (2011). Actigen ${ }^{\mathrm{TM}}$ impact on broiler growth and production economics. "Science and Technology in the Feed Industry Conference". Proceedings of Alltech's 27th Annual International Symposium Lexington, Kentucky, USA.

2. Ferket PR, Santos AA Jr., Oviedo-Rondon EO, (2005). Dietary factors that affect gut health and pathogen colonization. Proceedings of the 32nd Carolina Poultry Nutrition Conference, October 26-27, 2005, Research Triangle Park, NC., USA., pp: 1-22.

3. Gernat A (2011). Actigen ${ }^{\mathrm{TM}}$ and $\mathrm{Zn}$ bacitracin: Comparative effects on performance, intestinal integrity and immunity of broilers. "Science and Technology in the Feed Industry" Conference. Proceedings of Alltech's 27th
Annual International Symposium Lexington, Kentucky, USA.

4. Hooge Danny M, Kiers A, Connolly A (2013). Meta-Analysis Summary of Broiler Chicken Trials with Dietary Actigen ${ }^{\mathrm{TM}}$ (2009-2012). International Journal of Poultry Science, 12: 1-8.

5. Lausten P, Nollet L (2011). Performance responses of broilers to Actigen ${ }^{\mathrm{TM}}$, a probiotic, or butanoic acid. "Science and Technology in the Feed Industry Conference". Proceedings of Alltech's 27th Annual International Symposium Lexington, Kentucky, USA.

6. Lea HK, Burton EJ (2011). Performance and gut health of poultry in the post-antibiotic era when feeding a novel yeast cell wall component. "Science and Technology in the Feed Industry" Conference. Proceedings of Alltech's 27th Annual International Symposium Lexington, Kentucky, USA.

7. Mathis GF (2012). Comparison of performance of commercial broilers fed Actigen versus or in combination with BMD/Stafac. Report 12-E-8363, Southern Poultry Research, Inc., Athens, GA., pp: 34.

8. Nollet L, Kay Z (2010). Actigen ${ }^{\mathrm{TM}}$ as a growth permitted in broilers. Scottish Agricultural College, UK., pp: 4.

9. Olejniczak R, Nollet L (2011). Evaluation of the effectiveness of Actigen ${ }^{\mathrm{TM}}$ as a growth promoter in broilers. "Science and Technology in the Feed Industry" Conference. Proceedings of Alltech's 27th Annual International Symposium Lexington, Kentucky, USA.

10. Peric L, Zikic D, Ivkovic M, (2010). Effect of different concentrations of Actigen on performance and intestinal development and function of broilers: Trial II. University of Novi Sad, Faculty of Agriculture, Department of Animal Science, Novi Sad, Serbia, pp: 6.

11. http://www.biomin.net/en/products/biotronic/ accessed on 27.07.2016 